\title{
Characterization and Release of Ibuprofen in Proniosome System (Ibuprofen-Span 60-Cholesterol) by Dewi Melani Hariyadi
}

Submission date: 11-Jun-2019 12:20PM (UTC+0800)

Submission ID: 1142414614

File name: C-10.pdf (219.99K)

Word count: 2381

Character count: 12387 
Available online on www.ijddt.com

International Journal of Drug Delivery Technology 2018; 8(2); 103-106

doi: $\underline{10.25258 / \mathrm{ijddt} . v 8 \mathrm{i} 2.13875}$

ISSN: 09754415

Research Article

\title{
Characterization and Release of Ibuprofen in Proniosome System (Ibuprofen-Span 60-Cholesterol)
}

\author{
Tutiek Purwanti*, Dewi Melani Hariyadi, Corry Silvia \\ Department of Pharmaceutics, Faculty of Pharmacy, Airlangga University, Surabaya, Indonesia
}

Received: $20^{\text {th }}$ Feb, 18; Revised: $25^{\text {th }}$ Mar, 18, Accepted: $10^{\text {th }}$ Apr, 18; Available Online: $25^{\text {th }}$ Jun, 2018

\begin{abstract}
The aim of this research was to determine influence of proniosome system which consists of ibuprofen-span 601 olesterol with molar ratio of 2:1:0.75. The proniosome system was made by Coacervation Phase Separation Method, using ethanol $96 \%$ as solvent and glycerol $0.1 \%$ as aqueous phase. There were two formulas in this research formula I was ibuprofen non proniosome in HPMC gel base and formula II was i1 uprofen proniosome in HPMC gel base. Characterization of formulas in 1 lided organoleptic and $\mathrm{pH}$ of ibuprofen gel. Drug release wa 1 determined using diffusion cell and cellophane membrane in phosphate buffer $\mathrm{pH} 6.0 \pm 0.05$ at temperature $32 \pm 0.5^{\circ} \mathrm{C}$ for 7 hours. The drug release (flux) of ibuprofen from formula 1 and II were $28.3067 \pm 3.0852 \mu \mathrm{g} / \mathrm{cm}^{2} / \mathrm{min}^{1 / 2}$ and $23.1900 \pm 1.7658 \mu \mathrm{g} / \mathrm{cm}^{2} / \mathrm{min}^{1 / 2}$, respectively. The statistical result using independent sample T-test on degree of confident of $95 \%(\alpha=0.05)$ concluded that there was significant value of their fluxs. Research result revealed that release of ibuprofen proniosome system was lower than ibuprofen nonproniosome system in HPMC 4000 gel base.
\end{abstract}

Keywords: proniosome, ibuprofen, drug release.

\section{INTRODUCTION}

Ibuprofen is a potent anti-inflammatory and an 10 esic drug that can be used to treat mild to severe pain such as dysmenorrhea, migraine, postoperative pain, ankylosing 9 ondylitis, osteoarthritis, and rheumatoid arthritis ${ }^{1}$ Mechanism of action of NSAIDs ibuprofen as inhibitors of cyclooxygenase (COX) non-selective, for example not only inhibit COX-2 which induces inflammation, but also inhibits COX-1 which controls the homeostasis of the body. At oral application, ibuprofen can interfere with the digestive tract and induce irritatin ${ }^{2}$. Topical preparations is an alternative application 80 reduce the side effects of ibuprofen. In the topical preparations, the active ingredient must be dissolved in the carrier and then released to the skin surface of the skin to penetrate through the membrane to reach the target of action so as to provide a t 7 rapeutic effect ${ }^{3}$. The release of drug from the carrier is influenced by several factors i 4 luding the chemical properties of the ingredients, the solubility of the drug in the carrier, the affinity of the drug to the carrier, the viscosity and $\mathrm{pH}$ preparations ${ }^{4}$.

Ibuprofen is practically insoluble in water (hydrophobic) and has a $\log$ P 3.5 and short half life at only 2 hours ${ }^{1}$. Therefore ibuprofen has less bioavailability. As an analgesic anti-inflammatory drug, ibuprofen is expected to have a rapid and long lasting effect. To solve these problems, ibuprofen was formulated in proniosome system.

Proniosome is a development of niosome aiming to increase the stability of niosome, because niosome is physically unstable. Proniosome will form a niosome after experience a hydration process, especially by a liquid on the skin surface. Proniosome is the vesicles system consisting of a non-ionic surfactant and cholesterol or other lipids that wraps hydrophilic phase and can be hydrated immediately with water to become a form niosome ${ }^{5}$. Vesicle is an active agent which encapsulated or entrapped in the vesicle system so that the amount of drug substance dissolved will increase. The first vesicle system that is widely used for the development of topical preparations are liposome but because it is expensive and the purity of the natural variation of phospholipids and natural instability, began to introduce the surfactant-based drug delivery systems known as niosome ${ }^{6}$.

Niosome is 6 microscopic lamellar structure, which is formed from a mixture of non-ionic surfactants with the addition of cholesterol or other lipids (eg, lecithin). Cholesterol serves to maintain the stability and permeability of the resulting vesicles. In addition, cholesterol also affects the efficiency of entrapment of active ingredient. Efficiency entrapping the active ingredient will increase with increasing the amount of cholesterol that is used ${ }^{7}$. However, the increase in cholesterol would reduce the rate of release of the entrapped drug ${ }^{8}$.

Niosome is an alternative to liposome because it has physical properties similar to liposome but greater stability and fewer disadvantages when compared with liposome ${ }^{6}$. Niosome system will entrap ibuprofen in the hydrophobic part of the vesicle while the hydrophilic groups on the outside of the vesicle will interact with the

"Author for Correspondence: tutiek_purwanti@yahoo.com 


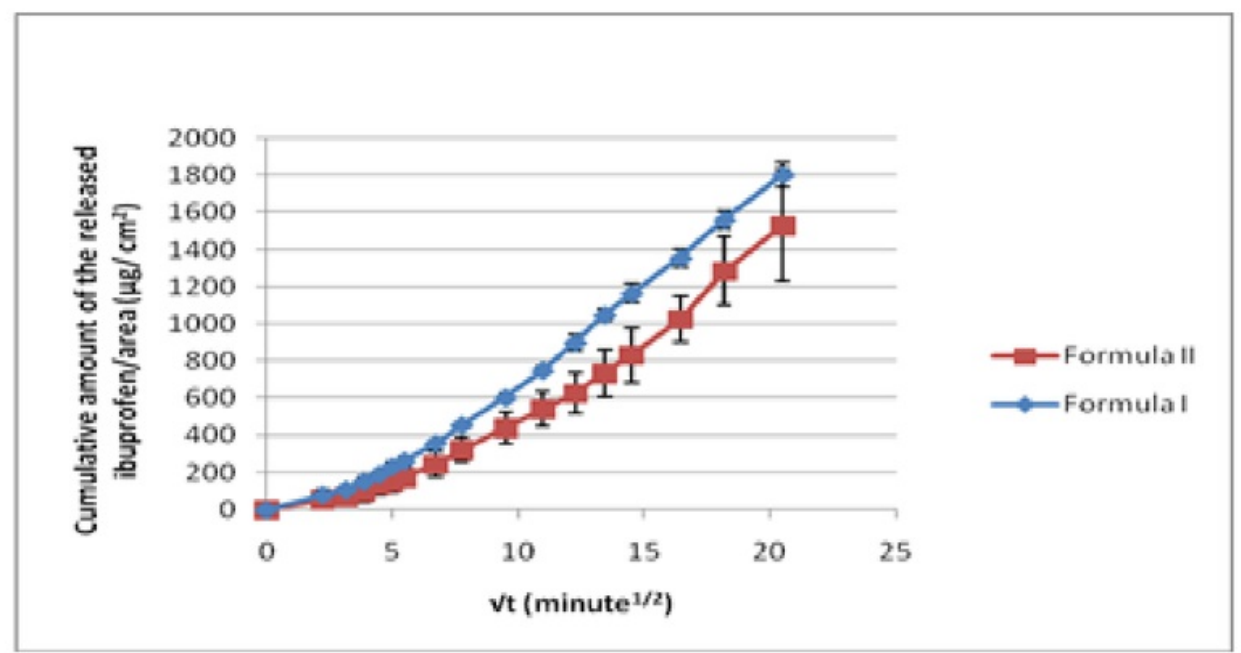

Figure 1: Cumulative Release of Ibuprofen from Gel Base.

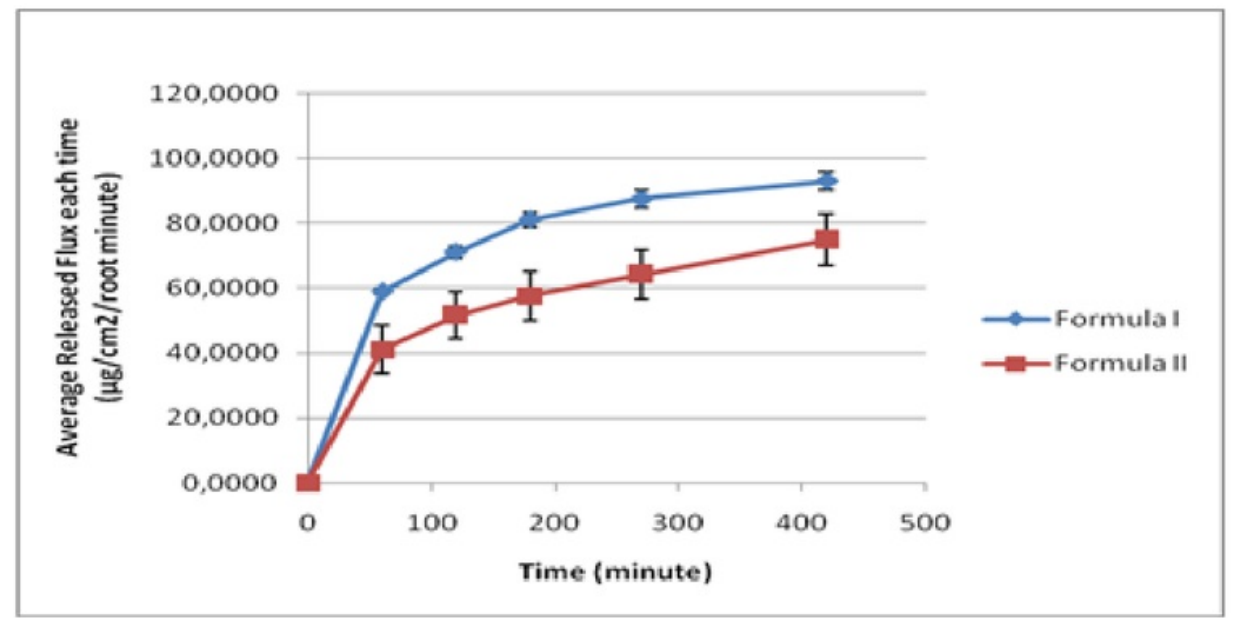

Figure 2: Release Flux of Ibuprofen.

Table 1: Proniosome composition.

\begin{tabular}{lcl}
\hline Component & Molar Ratio & Amount \\
\hline Ibuprofen & 2 & $200 \mathrm{mg}$ \\
Span 60 & 1 & $200 \mathrm{mg}$ \\
Cholesterol & 0.75 & $150 \mathrm{mg}$ \\
Ethanol $96 \%$ & & $175 \mu \mathrm{L}$ \\
Glycerol $0.1 \%$ & & $140 \mu \mathrm{L}$ \\
\hline
\end{tabular}

water phase so that the system can increase the distribution ibuprofen niosome. Entrapped drug in niosome also can be a depo which has controlled release ${ }^{8}$. Thus, the duration of action can be longer and has the optimal effects. The proniosome form is a liquid crystal gel which is in the semisolid phase. The release of drug from proniosome system is influenced by concentration of drug, type and composition of the surfactant, amount of cholesterol, type and amount of solvent, as well as type and amount of aqueous phase.

Ibuprofen proniosome was made using molar ratio
11 uprofen, span 60, and cholesterol 2:1:0.75 with ethanol $96 \%$ as solvent and $0.1 \%$ glycerol as an aqueous phase. The ibuprofen proniosome system than formulated in HPMC 4000 gel base. HPMC 4000 was selected as a gelling agent because HPMC is easily dispersed in water, did not require neutralization in its formulation, not sticky, and d 3 not cause irritation. Additionally, HPMC is stable in a wide $\mathrm{pH}$ range $(\mathrm{pH} \mathrm{3-11)}$ and is more resistant to microbial attack than the base gel derived from natural materials?

\section{MATERIALS AND METHODS}

\section{2hemicals}

Ibuprofen (Shasun Chemicals and Drugs Ltd., India), Span 60 (Sigma), kolesterol (Sigma), HPMC 4000 (ShinEtsu Chemical Co. Ltd), etanol 96\% (E. Merck), gliserol (E. Merck), propilenglikol (BASF SE), NaH2PO4.1H2O (E. Merck), Na2HPO4 (E. Merck). 
Table 2: Formula of Gels.

\begin{tabular}{llll}
\hline \multirow{2}{*}{ Component } & \multirow{2}{*}{$\begin{array}{l}\text { Concentr } \\
\text { ation }\end{array}$} & \multicolumn{2}{c}{ Amount } \\
\cline { 3 - 4 } & $5 \%$ & $0.500 \mathrm{~g}$ & - \\
\hline $\begin{array}{l}\text { Ibuprofen } \\
\text { Ibuprofen }\end{array}$ & $5 \%$ & - & $1.705 \mathrm{~g}$ \\
$\begin{array}{l}\text { proniosome } \\
\begin{array}{l}\text { Propylene } \\
\text { glycol }\end{array}\end{array}$ & $5 \%$ & $1 \mathrm{~g}$ & $1 \mathrm{~g}$ \\
$\begin{array}{l}\text { HPMC } 4000 \\
\text { gel base }\end{array}$ & ad $100 \%$ & ad $10 \mathrm{~g}$ & ad $10 \mathrm{~g}$ \\
\hline
\end{tabular}

* Amount of proniosome used was equivalent to $0.500 \mathrm{~g}$ ibuprofen

\section{Proniosome P 5 paration}

Proniosome was prepared by coaservation phase separation method using molar ratio of Ibuprofen : Span 60: Cholesterol $=2: 1: 0.75$ The formula can be seen in table 1. Formula I is ibuprofen gel and formula II is ibuprofen proniosome gel, each of which can be seen in table 2. After gel was made, the homogenity test of ibuprofen's concentration was conducted.

Characterization of ibuprofen gel

Characterization of ibuprofen gel included organoleptic and $\mathrm{pH}$. Drug release was d 1 ermined using diffusion cell and cellophane membrane in phosphate buffer $\mathrm{pH} 6.0 \pm$ 0.05 at temperature $32 \pm 0.5^{\circ} \mathrm{C}$ for 8 hours as shown in figure 1 and figure 2 .

\section{RESULTS}

The organoleptic observations showed that ibuprofen proniosome gel was more viscous and had less spreadibility than ibuprofen gel. The $\mathrm{pH}$ of formula II $(4.98 \pm 0.44)$ was greater than the formula I $(4.74 \pm 0.20)$ but not significantly different statistically. Both $\mathrm{pH}$ formulas were acceptable for skin $\mathrm{pH}$ range (4.0 to 6.8), so both these formulas did not cause irritation for topical uses. The result of homogenity tes concluded that ibuprofen concthtration of formula I and formula II were homogenous. The drug release (flux) of ibuprofen from formula I and II were $28.3067 \pm 3.0852 \mu \mathrm{g} / \mathrm{cm}^{2} / \mathrm{min}^{1 / 2}$ and $23.1900 \pm 1.7658 \mu \mathrm{g} / \mathrm{cm}^{2} / \mathrm{min}^{1 / 2}$, respectively.

\section{DISCUSSION}

In formula I, ibuprofen was dissolved completely in a gel state so it was readily liberated from the base and generated a considerable flux, while in formula II much ibuprofen was entrapped in proniosome hidrated (niosome), so that only little amount was ready to be separated from the base. Viscosity of gel could affect the mobility of the drug in the base, which may affect the release of drug. Therefore, in this research, formula II had smaller flux than formula I, but its release was longer than formula I due to drug depo function. This suggested to prolong time experiment for investigating the entire release process

$\mathrm{pH}$ affected on the effectiveness of the active ingredient and skin irritation for topical use. $\mathrm{pH}$ obtained in the formula II $(4.98 \pm 0.44)$ was greater than the formula I $(4.74 \pm 0.20)$, but not significantly difference and both $\mathrm{pH}$ still meet the skin's $\mathrm{pH}$ range $(4.0 \text { to } 6.8)^{10}$. This $\mathrm{pH}$ was not predicted to irritate the skin

Diameter spread of the dosage forms related to the acceptability of the preparation when used Measurements were made using glass that weighing 249.5 grams and was considered a zero load. Diameter spread of formula II $(5.5 \pm 0.4 \mathrm{~cm})$ was smaller than the formula I $(6.1 \pm 0.4 \mathrm{~cm})$, this result was according to the results of organoleptic where the formula II had thicker consistency than the formula I due to the addition proniosome the more viscous consistency, but the statistical test showed no significant differences. The final stage in this study was done was a release test of ibuprofen using a series of test equipi1 ent dissolution and diffusion cells with the test medium phosphate buffer $\mathrm{pH}$ $6.0 \pm 0.05$, temperature $32^{\circ} \mathrm{C}$, and the stirring speed of $100 \mathrm{rpm}$ for 7 hours. Release testing was conducted to determine the effect of proniosome system against the release of ibuprofen from gel base HPMC 4000. This study used the cellophane membrane to hold the formula out of the diffusion cell. In this study, the flux was calculated as the slope of the regression equation cumulative amount released versus ibuprofen root of time at steady state conditions. The average obtained flux ibuprofen for formula I $(93.1381 \pm 2.8618 \mathrm{~g} / \mathrm{cm} 2 /$ menit $\left.^{1 / 2}\right)$ was greater than the formula II $(66.9779 \pm$ $9.1962 \mathrm{~g} / \mathrm{cm}^{2} /$ menit $^{1 / 2}$.

Drug release from the dosage form was influenced by several factors, namely solubility and viscosity diffuse preparations ${ }^{11}$. In the formula I, ibuprofen was entirely in the dissolved state, therefore it was ready to be separated from the base and generate sizable flux. While the formula II, much ibuprofen proniosome entrapped in the system so that the amount of drug that was not entrapped and ready to be separated from fewer bases of the formula I. In fact a drug particles should be in the form of dissolved (molecular) in order to diffuse ${ }^{10}$ and separated from the base in order to achieve the difference amount of ibuprofen dissolved in both formulas that affect the release of ibuprofen resulting in flux of the formula II was lower than the formula I.

The viscosity of the preparation may influence the mobility of the active ingredient in the base, which will affect the release of the $\mathrm{drug}^{4}$. From the observation of spread diameter at zero load, it was known that the formula II had thicker consistency than formula I and had lower flux release compared to formula I. It showed that in this study the consistency of formula was significantly influenced the release of ibuprofen.

Proniosome system can be a depo, to lengthen the therapeutical period of drugs. A drug that was not entrapped in the system will be separated first while the ingredients are trapped in proniosome require a longer time to release due to having to penetrate the vesicle followed by diffuses through the gel and was then separated from the preparation ${ }^{12}$. Dissolution in 7 hours was not been able to show that extended drug release profile in the formula II, because of the proniosome system required a longer time to be separated entirely from the base when compared to the preparation with no proniosome system. Therefore to be able to see the 
overall release profile of this ibuprofen gel dosage forms, extended experimental period was highly recommended such as carrying out the study in minimum of 12 hours.

\section{CONCLUSION}

This study clearly demonstrated that release flux of ibuprofen in proniosome gel was lower than in ibuprofen non proniosome gel.

\section{REFERENCES}

1. Sweetman, S.C., 2009. Martindale The Complete Drug Reference, $36^{\text {th }}$ edition, London:

Pharmaceutical Press (PhP)

2. Katzung, B.G., 2007. Basic and Clinical Pharmacology, $10^{\text {th }}$ Edition, United States of America: The McGraw-Hill Companies, Inc.

3. Idson, B., and Lazarus, J., 1986. Semisolids. In: L. Lachman, H.A. Lieberman, and J.L. Kanig (Eds). The Theory and Practice of Industrial Pharmacy. Philadelphia: Lea and Febiger.

4. Carter, S.J., 1986. Dispensing for Pharmaceutical Students, $12^{\text {th }}$ Edition, London: Pitman Medical Publishing Co. Ltd., pp. 227.

5. Sudhamani, T., Priyadarisini, N., and Radhakrishnan, M., 2010. Proniosomes - A Promising Drug Carriers. International Journal of Pharm Tech Research, Vol.2, No.2, pp. 1446-1454
6. Maibach, H.I., and Choi, M.J., 2005. Liposomes and Niosomes as Topical Drug Delivery Systems. Skin Pharmacol Physiol, Vol. 18, pp. 209-219.

7. Mokhtar, M., Sammour, O.A., Hammad, M.A., and Megraba, N.A., 2008. Effect of Some Formulation Parameters on Flurbiprofen Encapsulation and Release Rates of Niosomes Prepared from Proniosomes. International Journal of Pharmaceutics, pp. 104-111

8. Tangri, P., and Khurana, S., 2011. Niosomes: Formulation and Evaluation. International Journal of Biopharmaceutic, Vol. 2, No. 1, pp. 47-53.

9. Rowe, R.C., Sheskey, P.J., and Quinn, M.E., 2009 Handbook of Pharmaceutical Excipients, $6^{\text {th }}$ Edition, London: Pharmaceutical Press (PhP).

10. Sinko, PJ., 2012. Martin's Physical Pharmacy and Pharmaceutical Sciences $6^{\text {th }}$ Edition, New Jersey, pp 441-445.

11. Barry, B.W., 1983. Dermatological Formulation Percutaneous Absorption. New York: Marcel Dekker, Inc.

12. Kapoor, A., Gahoi, R., Kumar, D., (2011) In vitro drug release profile of Acyclovir from Niosomes formed with different Sorbitan esters. Asian Journal of Pharmacy \& Life Science, 1 (1), pp 64-69. 
Characterization and Release of Ibuprofen in Proniosome System (Ibuprofen-Span 60-Cholesterol)

ORIGINALITY REPORT

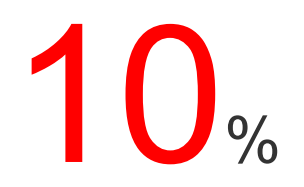

SIMILARITY INDEX
$9 \%$

INTERNET SOURCES
$2 \%$

PUBLICATIONS
$0 \%$

STUDENT PAPERS

PRIMARY SOURCES

1 repository.unair.ac.id

Internet Source

2 journal.unair.ac.id

Internet Source

3 link.springer.com

Internet Source

4 dl4a.org

Internet Source

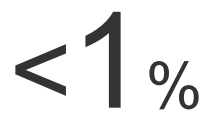

5 ajpls.com

6 M.Jayne Lawrence, Gareth D. Rees.

"Microemulsion-based media as novel drug delivery systems", Advanced Drug Delivery

Reviews, 2000

Publication

7 epdf.tips 
8 Gidwani. "Carrier-Based Drug Delivery System for Treatment of Acne", The Scientific World Journal, 2014

Publication

9 cdn.intechweb.org

10 B Luppi. "pH-sensitive polymeric physicalmixture for possible site-specific delivery of ibuprofen", European Journal of

Pharmaceutics and Biopharmaceutics, 2003

Publication 